Article

\title{
Enhanced Electrocatalytic Activity and Stability toward the Oxygen Reduction Reaction with Unprotected Pt Nanoclusters
}

\author{
Jing Liu ${ }^{1,2}$, Jiao Yin ${ }^{1}$, Bo Feng ${ }^{1}$, Tao $\mathrm{Xu}^{3, *}$ and Fu Wang ${ }^{1, *(\mathbb{C}}$ \\ 1 Laboratory of Environmental Sciences and Technology, Xinjiang Technical Institute of Physics \& Chemistry, \\ and Key Laboratory of Functional Materials and Devices for Special Environments, \\ Chinese Academy of Sciences, Urumqi 830011, China; liujing@ms.xjb.ac.cn (J.L.); yinjiao@ms.xjb.ac.cn (J.Y.); \\ fengb1008@163.com (B.F.) \\ 2 University of Chinese Academy of Sciences, No. 19 Yuquan Road, Beijing 100049, China \\ 3 Department of Chemistry and Biochemistry, Northern Illinois University, DeKalb, IL 60115, USA \\ * Correspondence: txu@niu.edu (T.X.); wangfu@sjtu.edu.cn (F.W.); Tel.: +86-021-547-42824 (F.W.)
}

Received: 3 November 2018; Accepted: 16 November 2018; Published: 20 November 2018

\begin{abstract}
The Pt particles within diameters of 1-3 nm known as Pt nanoclusters (NCs) are widely considered to be satisfactory oxygen reduction reaction (ORR) catalysts due to higher electrocatalytic performance and cost effectiveness. However, the utilization of such smaller Pt NCs is always limited by the synthesis strategies, stability and methanol tolerance of Pt. Herein, unprotected Pt NCs $(\sim 2.2 \mathrm{~nm})$ dispersed on carbon nanotubes (CNTs) were prepared via a modified top-down approach using liquid $\mathrm{Li}$ as a solvent to break down the bulk Pt. Compared with the commercial $\mathrm{Pt} / \mathrm{C}$, the resultant $\mathrm{Pt}$ NCs/CNTs catalyst (Pt loading: $10 \mathrm{wt} . \%$ ) exhibited more desirable ORR catalytic performance in $0.1 \mathrm{M} \mathrm{HClO}_{4}$. The specific activity (SA) and mass activity (MA) at $0.9 \mathrm{~V}$ for ORR over Pt NCs/CNTs were 2.5 and 3.2 times higher than those over the commercial Pt/C (Pt loading: $20 \mathrm{wt} . \%$ ). Meanwhile, the Pt NCs/CNTs catalyst demonstrated more satisfactory stability and methanol tolerance. Compared with the obvious loss ( 69\%) of commercial $\mathrm{Pt} / \mathrm{C}$, only a slight current decrease $(\sim 10 \%)$ was observed for Pt NCs/CNTs after the chronoamperometric measurement for $2 \times 10^{4} \mathrm{~s}$. Hence, the as-prepared Pt NCs/CNTs material displays great potential as a practical ORR catalyst.
\end{abstract}

Keywords: ORR; unprotected; Pt nanoclusters; carbon nanotubes; electrocatalysis

\section{Introduction}

The oxygen reduction reaction (ORR) is a vital component in fuel cells. Currently, Pt-based nanomaterials are the most effective catalysts to improve the ORR performance [1]. However, they suffer from a series of drawbacks including high costs, unsatisfactory catalytic activity, poor stability and lower methanol tolerance [2,3]. Hence, a large number of research articles have been focusing on figuring out these problems [4-6]. Among a wide variety of strategies, reducing the size of Pt into smaller size less than $3 \mathrm{~nm}$ referred as nanoclusters (NCs) has been frequently highlighted in that $\mathrm{Pt}$ NCs present more satisfactory ORR performance compared with larger Pt nanoparticles (NPs) because of the smaller size, narrower size distribution and more active sites [7-9]. More importantly, the smaller size endows $\mathrm{Pt}$ NCs with a large proportion of low-coordinated surface atoms, which is helpful for the adsorption and activation of $\mathrm{O}_{2}$ on the catalyst surface [10]. As a consequence, $\mathrm{Pt} \mathrm{NC}$ catalysts adopted in ORR can both dramatically enhance the electrocatalytic activity and lower the cost of Pt. However, Pt NCs usually require to be protected by the stabilizing agents to prevent the aggregation, which would hinder the mass transfer process and electron transportation and thus give 
rise to a sharp reduction in the electrochemical performance [11]. Consequently, developing more versatile preparation methods without any stabilizing agents to promote unprotected Pt NCs with improved electrocatalytic performance in ORR is highly desirable.

Among various fabrication strategies for the preparation of unprotected $\mathrm{Pt} \mathrm{NCs}$, the top-down approach is regarded as one of the most effective methods to relatively regulate the uniform distribution of particle size and control the particle size within 1-3 nm [12]. In particular, this method not only involves no protecting agents but also avoids chloride contamination which will also likely cause the loss of catalytic activity as protecting agents $[13,14]$. For example, Vulcan XC-72R carbon black supported $\mathrm{Pt}(\mathrm{Pt} /$ Vulcan XC-72R) with a mean particle size of $1.9 \pm 0.3 \mathrm{~nm}$ was synthesized via this method. Though the Pt/Vulcan XC-72R exhibited improved ORR activity compared with commercial $\mathrm{Pt} / \mathrm{C}$, it is far from to meet the requirement for practical application of fuel cells. In addition, the stability of the Pt/Vulcan XC-72R is unsatisfactory and the Pt loading on the substrate of Vulcan XC-72R was up to $15 \mathrm{wt} . \%$. Hence, how to continue to lower the mass loading and boost the electrocatalytic performance and stability of unprotected Pt NCs stemmed from the top-down approach are urgently needed to be addressed.

Furthermore, the substrates to uniformly load and anchor the unprotected $\mathrm{Pt} \mathrm{NCs}$ also make great contributions to promoting catalytic activity and stability for ORR. In particular, the strong interactions between the support and $\mathrm{Pt} \mathrm{NCs}$ can prevent the dissolution and aggregation of $\mathrm{Pt} \mathrm{NCs}$ during the ORR process [15]. Among a wide variety of available supporting materials, CNTs have been proposed as one of the most promising matrixes because of the high resistance to electrochemical oxidation and corrosion, high electronic conductivity, and low cost [16-18]. More importantly, the graphitic structure endows CNTs with higher electrochemical stability and quicker electron transfer rate, which is beneficial for both improving the ORR performance and stability $[19,20]$. Hence, CNTs as supporting material would give rise to an enhanced ORR activity and stability.

In the present work, a modified top-down method was proposed to fabricate unprotected Pt NCs anchored on CNTs with the average particle size of $\sim 2.2 \mathrm{~nm}$. The as-prepared Pt NCs/CNTs- $10 \%$ demonstrated more desirable ORR activity in $0.1 \mathrm{M} \mathrm{HClO}_{4}$. The specific activity (SA) and mass activity (MA) over Pt NCs/CNTs-10\% at $0.9 \mathrm{~V}$ were calculated to be $0.194 \mathrm{~mA} \mathrm{~cm}^{-2}$ and $167 \mathrm{~mA} \mathrm{mg}^{-1}$, respectively, which were 2.5 times and 3.2 times higher than those of $\mathrm{Pt} / \mathrm{C}-20 \%\left(0.079 \mathrm{~mA} \mathrm{~cm}{ }^{-2}\right.$ and $\left.52 \mathrm{~mA} \mathrm{mg}^{-1}\right)$. Notably, such a sample also exhibited remarkably higher stability and methanol tolerance than commercial $\mathrm{Pt} / \mathrm{C}-20 \%$. Compared with the obvious loss $(\sim 69 \%)$ of commercial $\mathrm{Pt} / \mathrm{C}$, only a slight current decrease $(\sim 10 \%)$ was observed after the chronoamperometric measurement for $2 \times 10^{4} \mathrm{~s}$. Thus, the as-prepared Pt NCs/CNTs-10\% holds great potential as a practical ORR catalyst.

\section{Materials and Methods}

\subsection{Materials}

Commercial Pt/C catalyst (Pt loading: $20 \mathrm{wt} . \%$ ) and carbon nanotubes were obtained from Adamas-beta (Shanghai, China). Lithium and platinum foil, perchloric acid (70\%) were purchased from Alfa-Aesar (Shanghai, China). Absolute ethyl alcohol and methanol were supplied by Tianjin Zhi yuan Chemical Reagent Co., Ltd (Tianjin, China). Nafion (5\%) were purchased from Sigma-aldrich (Saint Louis, MO, USA).

\subsection{Synthesis of Pt NCs/CNTs-10\%}

Synthesis of Pt NCs was carried out through a modified top-down approach in an Ar-filled glovebox. $2.1 \mathrm{~g}$ of $\mathrm{Li}$ was heated to $235^{\circ} \mathrm{C}$ in a nickel crucible, to which $20 \mathrm{mg} \mathrm{Pt}$ foil was added simultaneously. The mixture was sonicated at $235^{\circ} \mathrm{C}$ for $5 \mathrm{~h}$ to achieve a homogeneous dispersion. Then the Li-Pt molten was poured onto a stainless plate and removed from the glovebox. By cutting into small pieces, $\mathrm{Li}$ was slowly converted to $\mathrm{LiOH}$ under vapor water. $180 \mathrm{mg}$ of CNTs was added into the $\mathrm{LiOH}$. The mixture was pestled for $30 \mathrm{~min}$. The $\mathrm{LiOH}$ was isolated with distilled water 
leaving the Pt NCs on the CNTs support (Pt NCs/CNTs). The Pt NCs/CNTs was washed five times with distilled water and then dried at $60{ }^{\circ} \mathrm{C}$ in vacuum for $12 \mathrm{~h}$. The sample with $10 \mathrm{wt} . \% \mathrm{Pt}$ loading and the commercial Pt/C with $20 \mathrm{wt}$ \% Pt loading are denoted as Pt NCs/CNTs-10\% and $\mathrm{Pt} / \mathrm{C}-20 \%$, respectively.

\subsection{Characterizations}

X-ray diffraction (XRD) patterns were performed with samples on a Bruker D8 diffractometer, (Karlsruhe, Germany). Transmission electron microscope (TEM) images were obtained with a FEI f20. The lattice-resolved images were obtained by high-resolution TEM (HRTEM, FEI f20, Hillsboro, OR, USA). The Energy dispersive X-ray spectroscopy (EDS) was obtained by the EDS8000. X-ray photoelectron spectroscopy (XPS) was obtained on a KRATOS Analytical AXISHSi spectrometer (Kanagawa, Japan). $\mathrm{N}_{2}$ adsorption/desorption isotherms were made on Micromeritics ASAP2020 (Norcross, GA, USA). The inductively coupled plasma-optical emission spectrometry (ICP-OES) data were obtained on VISTA-PRO CCD (Chicago, IL, USA).

\subsection{Electrocatalytic Measurements}

Cyclic voltammograms (CV) and rotating disk electrode (RDE, Pine Instrument, Hong Kong, China) measurements were conducted on CHI660E to evaluate the ORR performance. All data were recorded at room temperature in a three-electrode cell in $0.1 \mathrm{M} \mathrm{HClO}_{4}$. Pt foil and $\mathrm{Ag} / \mathrm{AgCl}$ electrodes are used as counter electrode and reference electrode, respectively. All potentials in this work are reported versus reversible hydrogen electrode (RHE) via converting the measured potentials using Equation (1):

$$
E_{R H E}=\mathrm{E}_{\mathrm{Ag} / \mathrm{AgCl}}+0.059 \times p H+0.197
$$

Prior to the CV and RDE measurements, the glassy carbon electrode was polished with $0.3 \mu \mathrm{m}$ alumina slurries (Buehler, IL, USA) to a mirror finish and then washed and ultrasonically cleaned in ultrapure water for $3 \mathrm{~min}$. The $0.1 \mathrm{M} \mathrm{HClO}_{4}$ electrolyte was saturated with $\mathrm{O}_{2}(99.999 \%), \mathrm{N}_{2}(99.999 \%)$ or Ar (99.999\%). The working electrode was prepared as follows: Suspend $6 \mathrm{mg}$ Pt NCs/CNTs-10\% in the mixture of Nafion $(25 \mu \mathrm{L}, 5 \mathrm{wt} . \%)$ and $\mathrm{C}_{2} \mathrm{H}_{5} \mathrm{OH}(475 \mu \mathrm{L})$ and then sonicated for $30 \mathrm{~min}$ to obtain a homogeneous suspension. $10 \mu \mathrm{L}$ of the suspension was deposited on the $\Phi 5 \mathrm{~mm}$ glassy carbon disk and dried in air. The Pt loading on the glassy carbon was $\sim 0.06 \mathrm{mg} \mathrm{cm}^{-2}$. CV data were measured between 0 and $1.2 \mathrm{~V}$ at $50 \mathrm{mV} \mathrm{s}^{-1}$. RDE data were obtained at $10 \mathrm{mV} \mathrm{s}^{-1}$. The stability and the methanol tolerance of Pt NCs/CNTs-10\% were investigated by the chronoamperometric measurement.

\section{Results and Discussion}

\subsection{Physicochemical Characterizations}

XRD patterns are conducted to characterize the crystal structure of $\mathrm{Pt}$ NCs/CNTs $-10 \%$. As depicted in Figure 1, a typical fcc crystal phase is found for Pt NCs/CNTs-10\%. The as-prepared Pt NCs/CNTs-10\% exhibits the same diffraction patterns as the standard Pt card (JCPDS: 04-0802). The XRD pattern of CNT support displays two peaks at $\sim 25.7^{\circ}$ and $\sim 42.5^{\circ}$ assigned to the (002) and (100) reflections, respectively [21]. The (002) peak is also clearly observed in the XRD pattern of $\mathrm{Pt}$ NCs/CNTs-10\%. The (100) peak is weak and overlapped by the diffraction at $\sim 46.2^{\circ}$ attributed to the Pt (200) reflection. The mean particle size of Pt NCs is calculated to be $2.4 \mathrm{~nm}$ from the Pt (111) diffraction using the Scherrer equation. The geometric surface area of Pt NCs is determined to be $116.8 \mathrm{~m}^{2} \mathrm{~g}^{-1}$ from the XRD analysis using the Equation (2):

$$
\mathrm{s}=\frac{6000}{\rho d}
$$


where $\rho$ is the density of $\mathrm{Pt}\left(21.4 \mathrm{~g} \mathrm{~cm}^{-3}\right)$ and $\mathrm{d} / \mathrm{nm}$ is the average particle size determined by the XRD pattern.

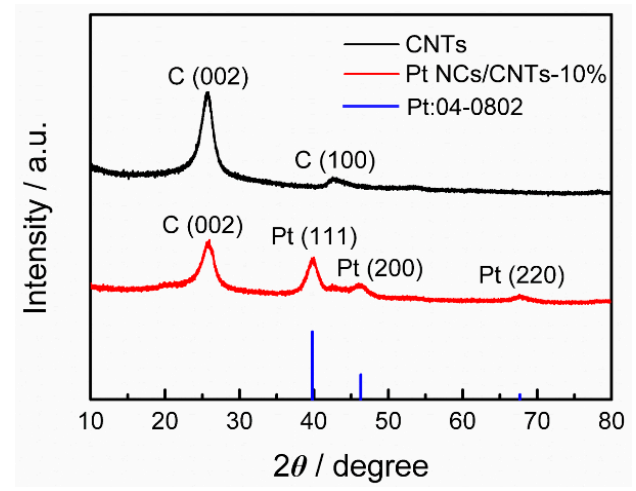

Figure 1. X-ray diffraction (XRD) patterns of the carbon nanotubes (CNTs), Pt NCs/CNTs-10\%, and standard bulk Pt.

Figure 2a shows the representative TEM image of Pt NCs/CNTs- $10 \%$. It can be seen that the Pt NCs are uniformly dispersed on CNTs with average diameter size of $2.2 \pm 0.35 \mathrm{~nm}$ (Figure 2b), which is consistent with the XRD result $(2.4 \mathrm{~nm})$. The inset of Figure 1 shows the HRTEM image of the Pt NCs. The Pt (111) surface orientation is determined through investigating the distance between two columns of Pt atoms. The corresponding elemental mapping (Figure 2c,d) and selected-area EDS (Figure 2e) analyses further clearly demonstrate the uniform distribution of Pt NCs on the CNTs. According to the ICP-OES analysis, the Pt mass loading is about $8.7 \%$, which slightly dropped from the theoretical value of $10 \%$ probably caused by the limited surface area of CNTs, which is determined to be $253 \mathrm{~m}^{2} \mathrm{~g}^{-1}$ according to the $\mathrm{N}_{2}$ absorption/desorption isotherms (Figure 3). The Brunauer-Emmett-Teller (BET) surface area of $\mathrm{Pt}$ NCs/CNTs- $10 \%$ and $\mathrm{Pt} / \mathrm{C}-20 \%$ are also carried out, which are determined to be $217 \mathrm{~m}^{2} \mathrm{~g}^{-1}$ and $411 \mathrm{~m}^{2} \mathrm{~g}^{-1}$, respectively. Obviously, the BET surface area of Pt NCs/CNTs-10\% is smaller than that of CNTs, which can be ascribed to the framework shrinkage during the process of preparing the catalyst.
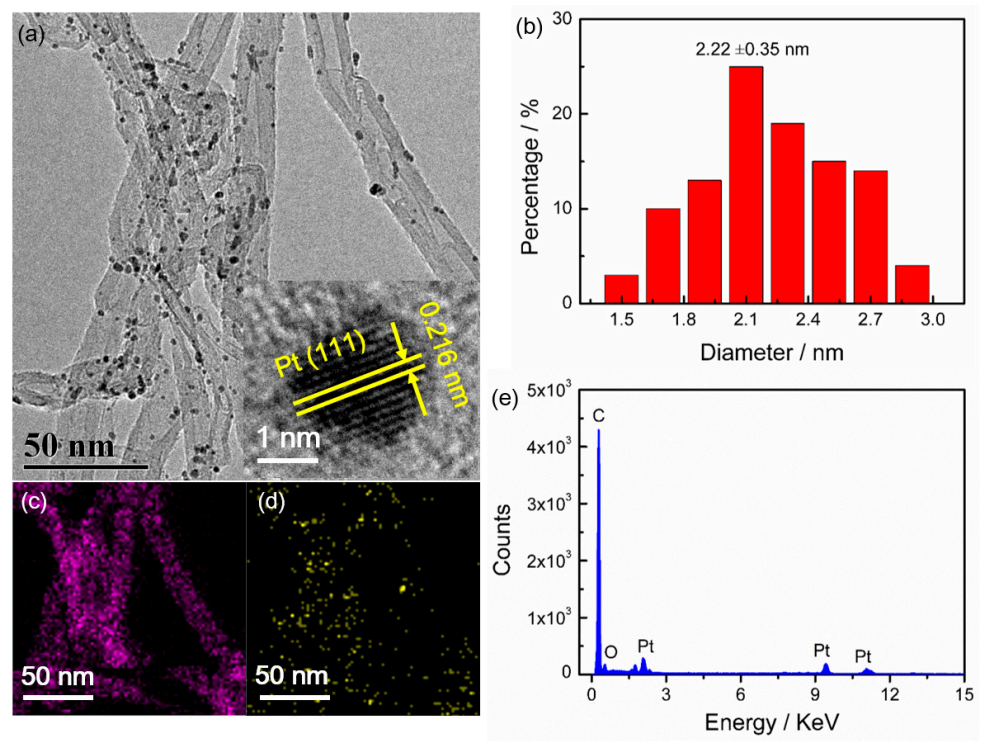

Figure 2. (a) Transmission electron microscope (TEM) image; (b) histograms of Pt NCs size distribution; (c) C mapping; (d) Pt mapping and (e) Energy dispersive X-ray spectroscopy (EDS) spectrum of Pt NCs/CNTs- $10 \%$. 

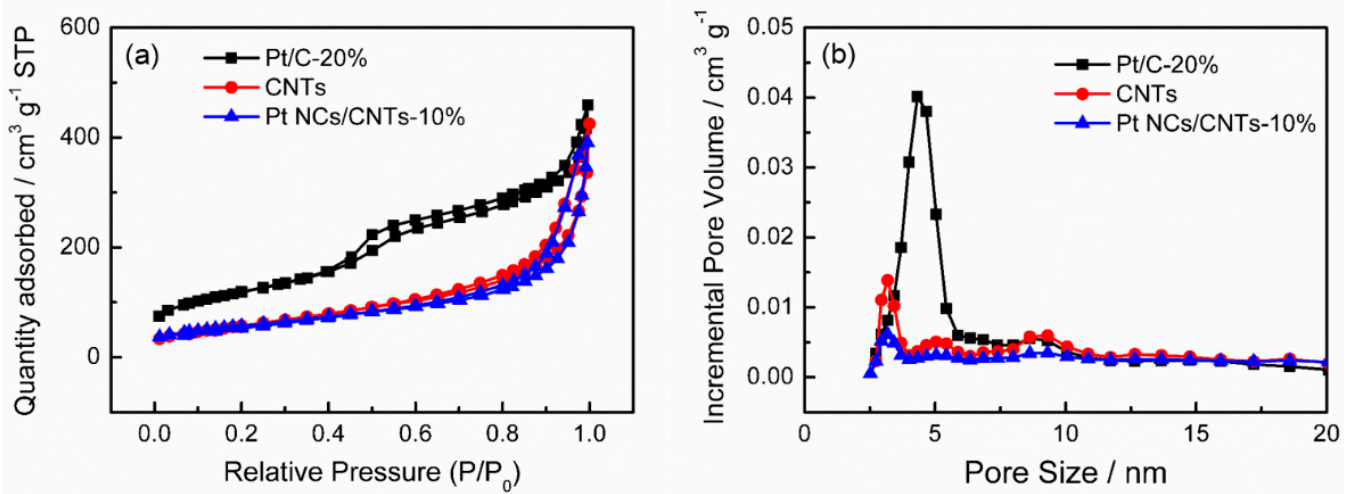

Figure 3. (a) $\mathrm{N}_{2}$ adsorption/desorption isotherms and (b) pore size distributions of CNTs, $\mathrm{Pt}$ NCs/CNTs-10\%, and Pt/C-20\%.

XPS measurement is employed to analyze the chemical states of Pt NCs. The C 1s peak at $284.6 \mathrm{eV}$ is adopted as a reference for the correction of the binding energy positions [22]. As shown in Figure 4a, both $\mathrm{C}$ and $\mathrm{Pt}$ are detected at their specific binding energy positions. As displayed in Figure $4 \mathrm{~b}$, high-resolution XPS spectrum of Pt $4 \mathrm{f}$ presents the characteristic peaks of $\mathrm{Pt}_{4} 4 \mathrm{f}_{7 / 2}$ and $\mathrm{Pt}_{4} \mathrm{f}_{5 / 2}$ at $\sim 71.4$ and $\sim 74.7 \mathrm{eV}$, respectively, which can be divided into two pairs of doubles. The peaks appeared at $\sim 71.35$ and $\sim 74.73 \mathrm{eV}$ are characteristic for metallic $\mathrm{Pt}^{0}$ [23]. The peaks located at 72.12 and $75.68 \mathrm{eV}$ are originated from $\mathrm{Pt}^{2+}$ [24]. Clearly, $\mathrm{Pt}^{0}$ is predominant. Based the deconvoluted XPS, it can be determined that the Pt NCs contain 69\% metallic Pt and 31\% Pt oxide. In addition, there is a slight shift of the $\mathrm{Pt}^{0}$ peak to higher binding energies, which may be attributed to the strong interactions between Pt NCs and CNTs [25], which are beneficial for improving the stability of Pt NCs/CNTs-10\%.
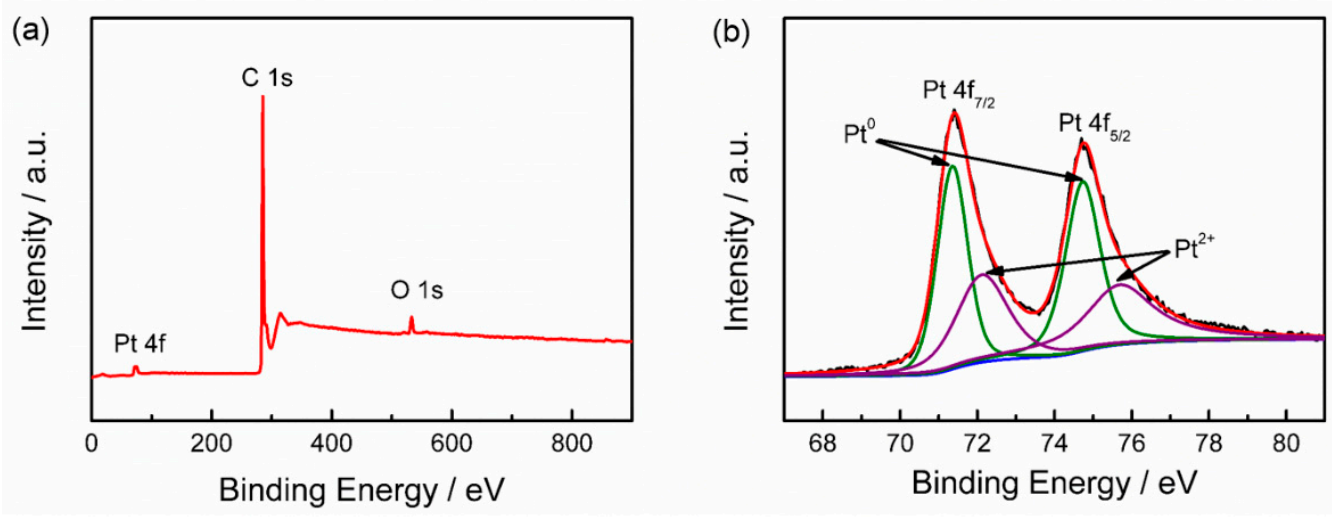

Figure 4. (a) Survey XPS spectrum and (b) Pt 4f spectrum of Pt NCs/CNTs-10\%.

\subsection{Electrochemical Evaluation}

Figure 5 shows the CVs of Pt NCs/CNTs-10\% and Pt/C-20\% in Ar-saturated $0.1 \mathrm{M} \mathrm{HClO}_{4}$ solution. A typical hydrogen adsorption/desorption behavior on $\mathrm{Pt}$ is clearly observed on both $\mathrm{Pt}$ NCs/CNTs- $10 \%$ and Pt $/ C-20 \%$. The electrochemical surface area $\left(E C S A, \mathrm{~m}^{2} \mathrm{~g}^{-1}\right.$ ) are calculated using Equation (3):

$$
\mathrm{ECSA}=\frac{\mathrm{Q}_{H}}{0.21 \times \mathrm{m}_{P t}}
$$

where $\mathrm{Q}_{H}(\mathrm{mC})$ is the charge due to the hydrogen adsorption in the hydrogen region of the $\mathrm{CV}$. $0.21\left(\mathrm{mC} \mathrm{cm}^{-2}\right)$ is the electrical charge associated with monolayer adsorption of hydrogen on Pt. $\mathrm{m}_{P t}$ is the Pt loading on working electrode. Results indicate that the ECSA of Pt NCs/CNTs- $10 \%$ and $\mathrm{Pt} / \mathrm{C}-20 \%$ are determined to be $48.23 \mathrm{~m}^{2} \mathrm{~g}^{-1}$ and $38.79 \mathrm{~m}^{2} \mathrm{~g}^{-1}$, respectively. The higher ECSA of $\mathrm{Pt}$ NCs/CNTs- $10 \%$ can be attributed to the small size and uniform distribution of Pt NCs on the CNTs. 


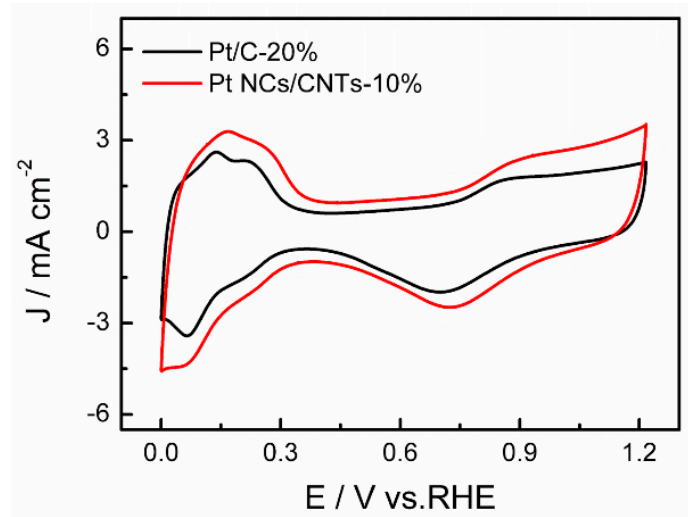

Figure 5. Cyclic voltammograms (CVs) of Pt NCs/CNTs-10\% and Pt/C-20\% in Ar-saturated $0.1 \mathrm{M}$ $\mathrm{HClO}_{4}$ at $50 \mathrm{mV} \mathrm{s}^{-1}$.

The RDE measurements for ORR are carried out in $\mathrm{O}_{2}$-saturated $0.1 \mathrm{M} \mathrm{HClO}_{4}$ at a potential scan rate of $10 \mathrm{mV} \mathrm{s}^{-1}$. Figure 6a exhibits the liner sweep voltammetry (LSV) curves of CNTs, $\mathrm{Pt}$ NCs/CNTs-10\% and Pt/C-20\% at the rotation rate of $1600 \mathrm{rpm}$. Obviously, it can be seen that the OMC is inactive for ORR. The diffusion and diffusion-kinetic controlled regions are found for $\mathrm{Pt}$ NCs/CNTs-10\% and Pt/C-20\% in the potentials below $0.65 \mathrm{~V}$ and $0.65-0.95 \mathrm{~V}$, respectively. It is worth mentioning that $\mathrm{Pt}$ NCs $/ \mathrm{CNTs}-10 \%$ possess a higher onset potential $\left(\mathrm{E}_{\text {onset }}=0.87 \mathrm{~V}\right)$ and half-wave potential $\left(\mathrm{E}_{1 / 2}=0.83 \mathrm{~V}\right)$ than that of $\mathrm{Pt} / \mathrm{C}-20 \%\left(\mathrm{E}_{\text {onset }}=0.86 \mathrm{~V}\right.$ and $\left.\mathrm{E}_{1 / 2}=0.81 \mathrm{~V}\right)$, indicating the higher ORR activity of Pt NCs/CNTs-10\%. Furthermore, the ORR diffusion limited current $\left(\mathrm{J}_{\mathrm{L}}\right)$ of $\mathrm{Pt}$ NCs/CNTs-10\% is higher compared with that measured for Pt/C-20\%. Figure 6b presents the tafel plots determined on the basis of the RDE data at $1600 \mathrm{rpm}$. The slope value for Pt NCs/CNTs-10\% is $81 \mathrm{mV}$ decade ${ }^{-1}$, which is smaller than that of Pt/C-20\% $\left(87 \mathrm{mV}\right.$ decade $\left.^{-1}\right)$, further indicating the more efficient ORR process on Pt NCs/CNTs-10\%.
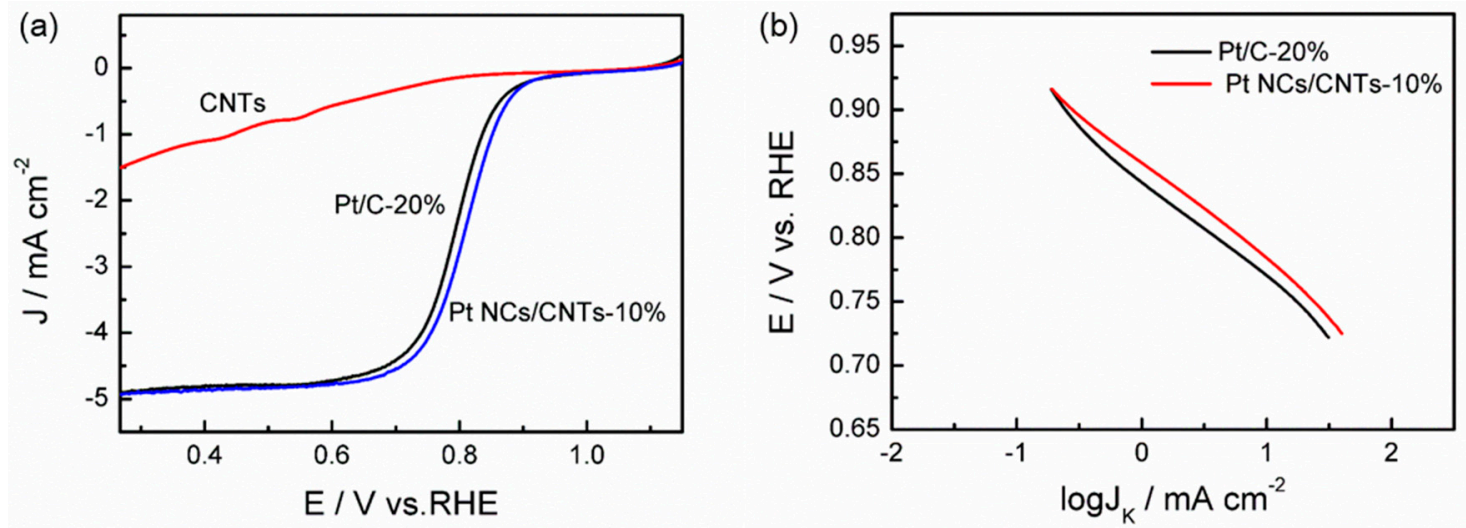

Figure 6. (a) Comparison of RDE polarization curves of Pt NCs/CNTs- $10 \%$ and $\mathrm{Pt} / \mathrm{C}-20 \%$ at $1600 \mathrm{rpm}$ in $\mathrm{O}_{2}$-saturated $0.1 \mathrm{M} \mathrm{HClO}_{4}$ solution at $10 \mathrm{mV} \mathrm{s}^{-1}$ and (b) Tafel plots for ORR derived from (a).

The LSV curves of Pt NCs/CNTs-10\% at different rotation speeds are further performed to clarify the ORR pathway. As displayed in Figure 7a, the LSV curves of Pt NCs/CNTs-10\% exhibit rotating-speed-dependent current densities. Potential in the diffusion and diffusion-kinetic regions, varying from 0.6 to $0.7 \mathrm{~V}$, was chosen to calculate the values of electron transfer number (n) by Koutecky-Levich (K-L) Equation (4):

$$
\frac{1}{\mathrm{~J}}=\frac{1}{\mathrm{~J}_{\mathrm{K}}}+\frac{1}{\mathrm{~J}_{\mathrm{L}}}=\frac{1}{\mathrm{~J}_{\mathrm{K}}}+\frac{1}{\mathrm{B \omega}^{1 / 2}}=\frac{1}{\mathrm{~J}_{\mathrm{K}}}+\frac{1}{0.62 \mathrm{nFCD} \mathrm{F}^{2 / 3} \mathrm{v}^{-1 / 6} \omega^{1 / 2}}
$$


where $\mathrm{J}, \mathrm{J}_{\mathrm{L}}$, and $\mathrm{J}_{\mathrm{K}}$ is the measured current, diffusion limited current, and kinetic current, respectively. $\omega$ is the electrode rotating rate. B is determined from the slope of the K-L plots. Faraday constant (F) is $96485 \mathrm{C}$. Diffusion coefficient (D) is $1.9 \times 10^{-5} \mathrm{~cm}^{2} \mathrm{~s}^{-1}$. Kinematic viscosity of the electrolyte $(v)$ is $0.01 \mathrm{~cm}^{2} \mathrm{~s}^{-1}$ and bulk concentration of $\mathrm{O}_{2}(\mathrm{C})$ is $1.2 \times 10^{-6} \mathrm{~mol} \mathrm{~cm}^{-3}$. As shown in Figure $7 \mathrm{~b}$, the corresponding K-L plots show excellent linearity, indicating the the first-order reaction kinetics. Meanwhile, the slopes of the K-L plots are almost same, suggesting a similar values of $\mathrm{n}$. Based on the K-L slopes, the value of $\mathrm{n}$ can be determined to be $3.80(0.60 \mathrm{~V}), 3.79(0.65 \mathrm{~V})$, and $3.81(0.70 \mathrm{~V})$, respectively. It suggests that $\mathrm{Pt} \mathrm{NC} / \mathrm{CNTs}-10 \%$ proceeds dominantly with a preferential $4 \mathrm{e}^{-}$pathway, which is beneficial to improve the efficiency of fuel cells.
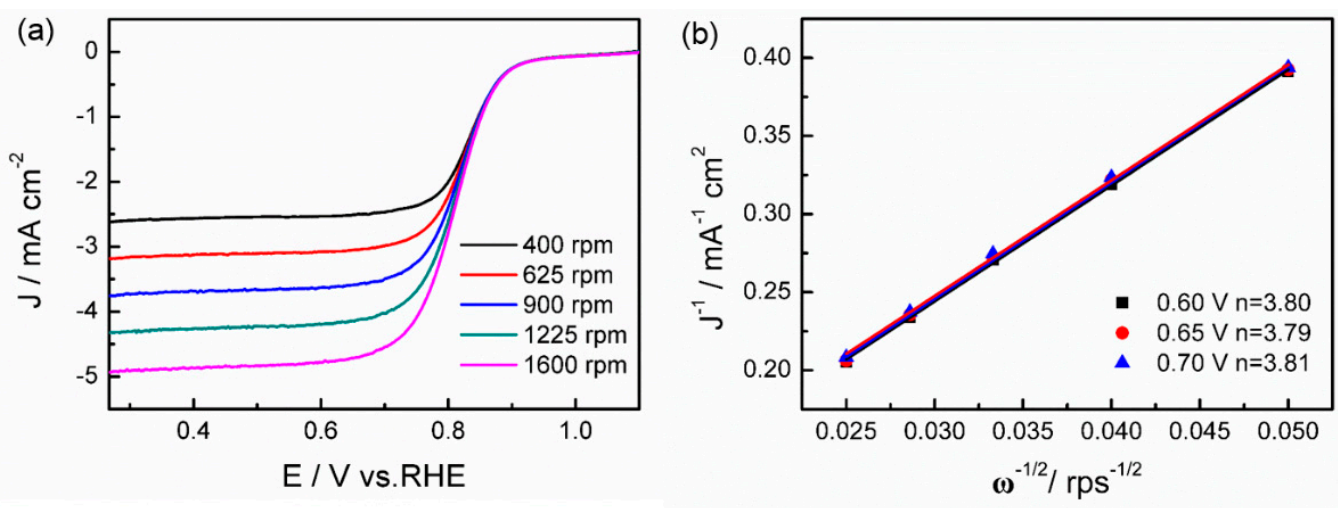

Figure 7. (a) RDE polarization curves for ORR on Pt NCs/CNTs- $10 \%$ at different rotation speeds from 400 to $1600 \mathrm{rpm}$ in $\mathrm{O}_{2}$-saturated $0.1 \mathrm{M} \mathrm{HClO}_{4}$ solution at $10 \mathrm{mV} \mathrm{s}^{-1}$ and (b) Corresponding $\mathrm{K}-\mathrm{L}$ plot at different potentials.

The SA and MA are important parameters for investigating intrinsic activities of catalysts. Here, the SA and MA of Pt NCs/CNTs-10\% and Pt/C-20\% are calculated from $\mathrm{J}_{\mathrm{K}}$ and normalization with the $\mathrm{Pt}$ surface area and loading, respectively. The $\mathrm{J}_{\mathrm{K}}$ is calculated from the mass-transport correction of RDE using Equation (5):

$$
\mathrm{J}_{\mathrm{K}}=\frac{\mathrm{J}_{\mathrm{L}} \times \mathrm{J}}{\mathrm{J}_{\mathrm{L}}-\mathrm{J}}
$$

As shown in Figure 8, at $0.85 \mathrm{~V}$, the SA over Pt NCs/CNTs-10\% $\left(0.482 \mathrm{~mA} \mathrm{~cm}{ }^{-2}\right)$ is 2.6 times larger than that of $\mathrm{Pt} / \mathrm{C}-20 \%\left(0.183 \mathrm{~mA} \mathrm{~cm}^{-2}\right)$ and the MA $\left(358 \mathrm{~mA} \mathrm{mg}^{-1}\right)$ is 4.1 times higher than that of Pt/C-20\% $\left(87 \mathrm{~mA} \mathrm{mg}^{-1} \mathrm{Pt}\right)$. These values over Pt NCs/CNTs- $10 \%$ at $0.9 \mathrm{~V}$ are calculated to be $0.194 \mathrm{~mA} \mathrm{~cm}^{-2}$ and $167 \mathrm{~mA} \mathrm{mg}^{-1}$ respectively, which are 2.5 and 3.2 times higher than those of $\mathrm{Pt} / \mathrm{C}-20 \%\left(0.079 \mathrm{~mA} \mathrm{~cm}^{-2}\right.$ and $\left.52 \mathrm{~mA} \mathrm{mg}^{-1}\right)$. The values of Pt NCs/CNTs- $10 \%$ are not only superior to that of Pt/C-20\%, but also that of most reported Pt-based catalysts as presented in Table 1.

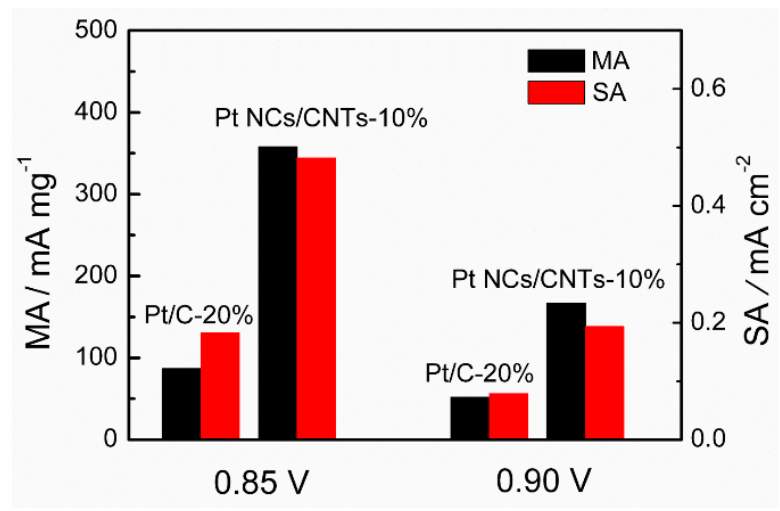

Figure 8. Mass activity (MA) and specific activity (SA) of Pt NCs/CNTs- $10 \%$ and Pt/C-20\% in $0.1 \mathrm{M}$ $\mathrm{HClO}_{4}$ at $0.85 \mathrm{~V}$ and $0.9 \mathrm{~V}$. 
Table 1. Comparison of ORR performances for the present Pt NCs/CNTs- $10 \%$ and the reported Pt-based catalysts in acid solution at 0.9 V. (NA: not available).

\begin{tabular}{|c|c|c|c|c|}
\hline \multirow{2}{*}{ Electroatalyst } & \multirow{2}{*}{ Pt Loading } & \multicolumn{2}{|c|}{ ORR Performances } & \multirow{2}{*}{ References } \\
\hline & & $\mathrm{MA} / \mathrm{mA} \mathrm{mg}^{-1}$ & $\mathrm{SA} / \mathrm{mA} \mathrm{cm}^{-2}$ & \\
\hline Pt NCs/CNTs & 8.7 wt. $\%$ & 167 & 0.194 & This work \\
\hline $\mathrm{Pt}_{1} \mathrm{Pd}_{3} / \mathrm{OMC}$ & 18.96 wt. $\%$ & 14.02 & 0.034 & [26] \\
\hline $\mathrm{Pt}_{3} \mathrm{Co} / \mathrm{C}$ & 18.1 wt. $\%$ & 321 & 0.501 & [27] \\
\hline $\mathrm{PtCo} / \mathrm{C}$ & 20 wt. $\%$ & 9.9 & 0.016 & [28] \\
\hline $\mathrm{Pd}_{80} \mathrm{Cu}_{6} \mathrm{Pt}_{14}$ & 23.5 wt. $\%$ & 420 & 0.5 & [29] \\
\hline Pt-Vulcan & NA & 117 & 0.19 & [30] \\
\hline $\operatorname{Pt}-\mathrm{Cr}(1: 1) / \mathrm{C}$ & 10 wt. $\%$ & 65 & 0.175 & [31] \\
\hline Pt nanocubes & 100 wt. $\%$ & NA & 0.113 & [32] \\
\hline $\mathrm{Pt} / \mathrm{GMC}$ & 22 wt. $\%$ & 140 & 0.208 & [33] \\
\hline $\mathrm{Pt} / \mathrm{MWCNT}$ & NA & 16.9 & 0.23 & {$[34]$} \\
\hline $\mathrm{Pt}_{0.65} \mathrm{Ni}_{0.35} / \mathrm{C}$ & 17.2 wt. $\%$ & 90 & 0.15 & [35] \\
\hline
\end{tabular}

The remarkable ORR activity of Pt NCs/CNTs-10\% catalyst can be attributed to the three factors: First, the reduced coordination of $\mathrm{Pt} \mathrm{NCs}$ as well as the decreased electrophilicity give rise to a corresponding reduction in the activation energy of the dissociative chemisorption of $\mathrm{O}_{2}$, facilitating the $4 \mathrm{e}^{-}$transfer process [36]. Second, the unprotected Pt NCs with smaller size and narrower size distribution can provide more active sites and promote the charge transfer during the ORR process. Third, CNTs with graphitic structure exhibit higher electron transfer rate [37]. All these together make the as-prepared Pt NCs/CNTs-10\% exhibit more desirable ORR performance.

\subsection{Electrochemical Stability and Methanol Tolerance}

Besides the ORR activity, the stability of catalysts are also important for the practical application of fuel cells. Here, the stability of Pt NCs/CNTs- $10 \%$ is performed by chronoamperometric measurement, which is an effective approach to investigate the stability of catalysts [38]. For comparison, $\mathrm{Pt} / \mathrm{C}-20 \%$ is also tested as a baseline catalyst. As shown in Figure 9, after chronoamperometric measurement for $2 \times 10^{4}$ s, only $\sim 10 \%$ current decrease is observed on Pt NCs/CNTs-10\%. However, the value for $\mathrm{Pt} / \mathrm{C}-20 \%$ is $\sim 69 \%$, much larger than that of $\mathrm{Pt}$ NCs/CNTs-10\%, demonstrating a more satisfactory stability of Pt NCs/CNTs-10\%. As reported in literatures, the poor stability of Pt/C-20\% is mainly derived from the agglomeration of Pt particles [39]. Hence, TEM image of Pt NCs/CNTs- $10 \%$ after the chronoamperometric measurement is conducted. As shown in Figure 10, no obvious aggregation is observed and the average particle size is determined to be $\sim 2.35 \pm 0.41 \mathrm{~nm}$. According to the aforementioned results, we can conclude that the excellent stability of Pt NCs/CNTs- $10 \%$ may be attributed to the trapping the Pt NCs in the CNTs nano-network as well as the interactions between $\mathrm{Pt}$ NCs and CNTs, suppressing the migration, aggregation, and growth in size of the small Pt NCs.

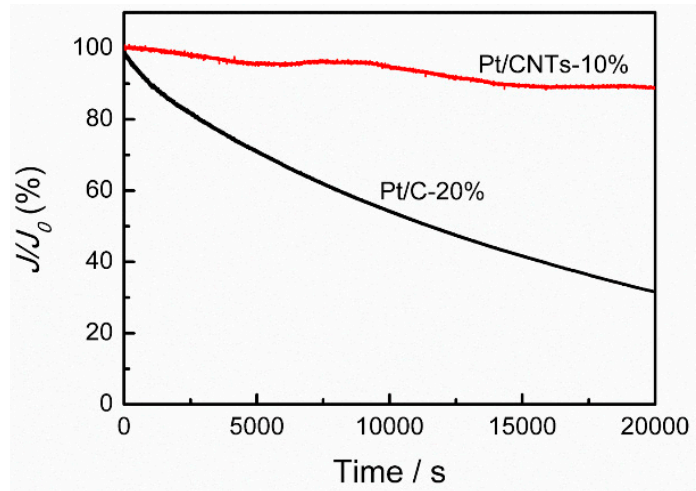

Figure 9. Relative current-time profiles of $\mathrm{Pt} \mathrm{NCs} / \mathrm{CNTs}-10 \%$ and $\mathrm{Pt} / \mathrm{C}-20 \%$ in $0.1 \mathrm{M} \mathrm{O}_{2}$-saturated $\mathrm{HClO}_{4}$. 

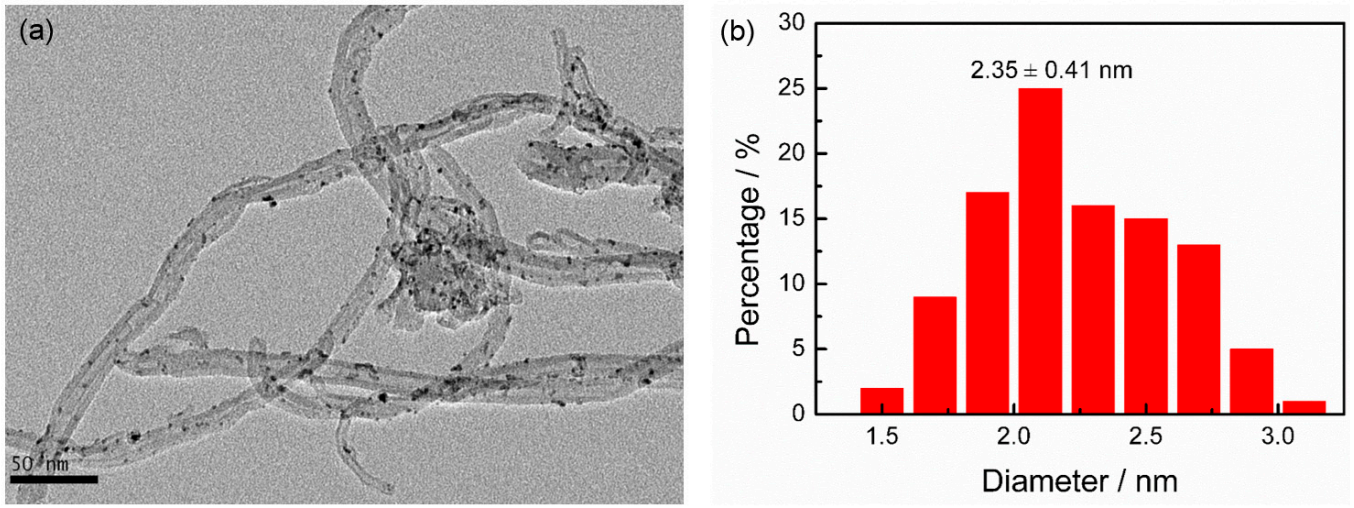

Figure 10. (a) TEM image and (b) size distribution of Pt NCs/CNTs-10\% after chronoamperometric measurement for $2 \times 10^{4} \mathrm{~s}$ in $\mathrm{O}_{2}$-saturated $0.1 \mathrm{M} \mathrm{HClO}_{4}$.

The crossover of methanol from the anode to the cathode can lead to a reduction in cell voltage by $\sim 200-300 \mathrm{mV}$. There is a competitive reaction between ORR and methanol oxidation on Pt-based cathodes. Therefore, it is highly desirable to develop ORR electrocatalysts with a high methanol tolerance for the application of fuel cells. Figure 11 displays the methanol tolerance of $\mathrm{Pt}$ NCs/CNTs- $10 \%$ and $\mathrm{Pt} / \mathrm{C}-20 \%$ evaluated by adding methanol into the electrolyte during the chronoamperometric measurement. It can be seen that the current of $\mathrm{Pt} / \mathrm{C}-20 \%$ decreases to $63 \%$ after methanol injection. In contrary, only a slight oscillation in the current is observed for $\mathrm{Pt}$ NCs/CNTs- $10 \%$, suggesting a great methanol tolerance of Pt NCs/CNTs- $10 \%$. The methanol oxidation in $0.1 \mathrm{M} \mathrm{N}_{2}$-saturated $\mathrm{HClO}_{4}$ solution containing $0.5 \mathrm{M} \mathrm{CH}_{3} \mathrm{OH}$ is further performed to analyze the origin of the high methanol tolerance of Pt NCs/CNTs- $10 \%$. As depicted in Figure $11 \mathrm{~b}$, the methanol oxidation current densities on Pt NCs/CNTs- $10 \%$ is $11.5 \mathrm{~mA} \mathrm{~cm}{ }^{-2}$, which is much smaller than that of $\mathrm{Pt} / \mathrm{C}-20 \%\left(49.4 \mathrm{~mA} \mathrm{~cm}^{-2}\right)$ implying that the methanol oxidation on Pt NCs/CNTs- $10 \%$ is less active than that on $\mathrm{Pt} / \mathrm{C}-20 \%$, which can be attributed to the hindrance of chemisorption of methanol on the catalyst surface. Thus, the high methanol tolerance of the Pt NCs/CNTs $-10 \%$ can be explained by the preferential adsorption of $\mathrm{O}_{2}$ over methanol on the Pt NCs site.
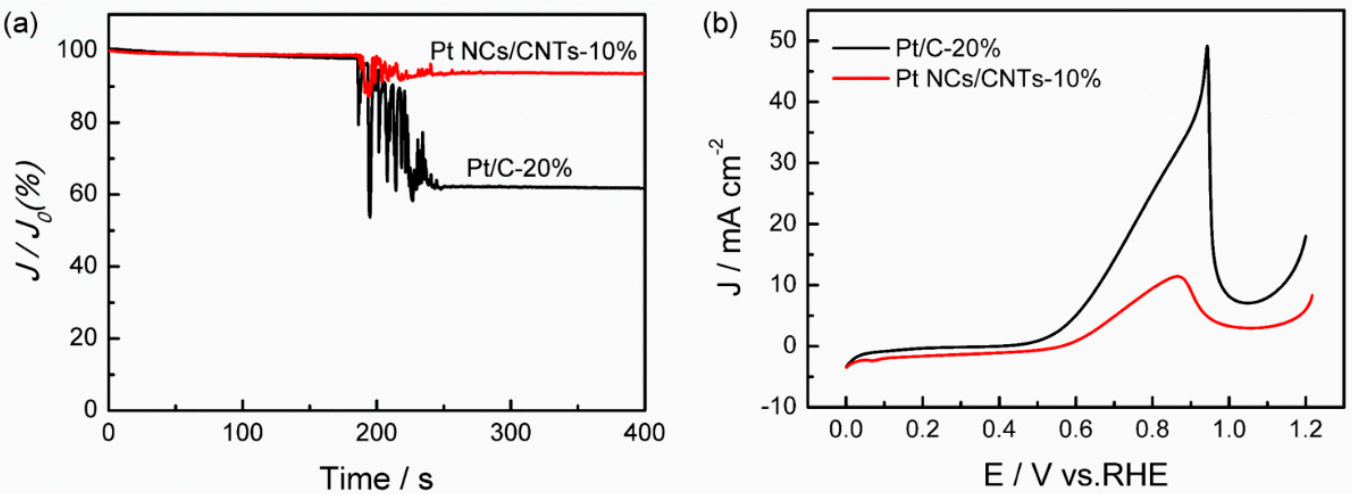

Figure 11. (a) Chronoamperometric responses of $\mathrm{Pt} \mathrm{NCs} / \mathrm{CNTs}-10 \%$ and $\mathrm{Pt} / \mathrm{C}-20 \%$ in $0.1 \mathrm{M}$ $\mathrm{O}_{2}$-saturated $\mathrm{HClO}_{4}$ before and after addition of methanol; (b) Polarization curves for methanol oxidation on Pt NCs/CNTs- $10 \%$ and Pt/C-20\% catalysts in $0.1 \mathrm{M} \mathrm{HClO}_{4}$ and $0.5 \mathrm{M} \mathrm{CH}_{3} \mathrm{OH}$ solution saturated with $\mathrm{N}_{2}$ at scan rate of $10 \mathrm{mV} \mathrm{s}^{-1}$.

\section{Conclusions}

In summary, highly dispersed Pt NCs $(\sim 2.2 \mathrm{~nm})$ anchored on CNTs were successfully fabricated through a modified top-down strategy. The Pt NCs/CNTs-10\% (Pt loading: $10 \mathrm{wt} . \%$ ) exhibited superior catalytic activity, stability, and methanol tolerance compared with $\mathrm{Pt} / \mathrm{C}-20 \%$. The enhanced activity of $\mathrm{Pt}$ NCs/CNTs-10\% is possibly ascribed to the reduced electrophilicity and the decreased coordination 
of the Pt NCs that lead to a decrease in the activation energy of $\mathrm{O}_{2}$, the smaller size and narrower size distribution of unprotected $\mathrm{Pt}$ NCs that provide more active sites, and the graphitic structure of CNTs that can improve the electron transfer rate. The Pt NCs/CNTs- $10 \%$ would be a promising catalyst for fuel cells.

Author Contributions: F.W. and T.X. conceived and designed the experiments; J.L. performed the major experiments; J.Y. and B.F. performed a part of the measurements; F.W. and J.L. analyzed the data and wrote the manuscript.

Funding: This work is financially supported by the National Natural Science Foundation of China (Grant No. 21503271), the National Key Research and Development Program of China, (Grant No. 2017YFC0110202) and the Foundation of Director of Xinjiang Technical Institute of Physics \& Chemistry, Chinese Academy of Sciences, (Grant No. 2016PY005).

Acknowledgments: We sincerely appreciate Yuanhao Wang (Xinjiang Technical Institute of Physics \& Chemistry, Chinese Academy of Sciences) for his effective suggestions.

Conflicts of Interest: The authors declare no conflict of interest.

\section{References}

1. Shao, M.; Chang, Q.; Dodelet, J.P.; Chenitz, R. Recent advances in electrocatalysts for oxygen reduction reaction. Chem. Rev. 2016, 116, 3594-3657. [CrossRef] [PubMed]

2. Seh, Z.W.; Kibsgaard, J.; Dickens, C.F.; Chorkendorff, I.; Norskov, J.K.; Jaramillo, T.F. Combining theory and experiment in electrocatalysis: Insights into materials design. Science 2017, 355, 4998-5011. [CrossRef] [PubMed]

3. Debe, M.K. Electrocatalyst approaches and challenges for automotive fuel cells. Nature 2012, 486, 43-51. [CrossRef] [PubMed]

4. Liu, Y.; Mustain, W.E. Structural and electrochemical studies of Pt clusters supported on high-surface-area tungsten carbide for oxygen reduction. ACS Catal. 2011, 1, 212-220. [CrossRef]

5. Zhang, L.; Fischer, J.; Jia, Y.; Yan, X.; Xu, W.; Wang, X.; Chen, J.; Yang, D.; Liu, H.; Zhuang, L.; et al. Coordination of atomic $\mathrm{Co}-\mathrm{Pt}$ coupling species at carbon defects as active sites for oxygen reduction Reaction. J. Am. Chem. Soc. 2018, 140, 10757-10763. [CrossRef] [PubMed]

6. Gu, W.; Shang, C.; Li, J.; Wang, E. Nitrogen-doped porous carbon matrix derived from metal-organic framework-supported Pt nanoparticles with enhanced oxygen reduction activity. ChemElectroChem 2017, 4, 2814-2818. [CrossRef]

7. Imaoka, T.; Kitazawa, H.; Chun, W.J.; Yamamoto, K. Finding the most catalytically active platinum clusters with low atomicity. Angew. Chem. Int. Ed. 2015, 54, 9810-9815. [CrossRef] [PubMed]

8. Imaoka, T.; Kitazawa, H.; Chun, W.J.; Omura, S.; Albrecht, K.; Yamamoto, K. Magic number $\mathrm{Pt}_{13}$ and misshapen $\mathrm{Pt}_{12}$ clusters: Which one is the better catalyst? J. Am. Chem. Soc. 2013, 135, 13089-13095. [CrossRef] [PubMed]

9. Yamamoto, K.; Imaoka, T.; Chun, W.J.; Enoki, O.; Katoh, H.; Takenaga, M.; Sonoi, A. Size-specific catalytic activity of platinum clusters enhances oxygen reduction reactions. Nat. Chem. 2009, 1, 397-402. [CrossRef] [PubMed]

10. Tiwari, J.N.; Nath, K.; Kumar, S.; Tiwari, R.N.; Kemp, K.C.; Le, N.H.; Youn, D.H.; Lee, J.S.; Kim, K.S. Stable platinum nanoclusters on genomic DNA-graphene oxide with a high oxygen reduction reaction activity. Nat. Commun. 2013, 4, 2221-2227. [CrossRef] [PubMed]

11. Li, D.; Wang, C.; Tripkovic, D.; Sun, S.; Markovic, N.M.; Stamenkovic, V.R. Surfactant removal for colloidal nanoparticles from solution synthesis: The effect on catalytic performance. ACS Catal. 2012, 2, 1358-1362. [CrossRef]

12. Tao, X.; Chikai, L.; Chao, W.; Dale, L.B.; Yasuo, I.; Jun, L. Synthesis of supported platinum nanoparticles from Li-Pt solid solution. J. Am. Chem. Soc. 2010, 132, 2151-2153.

13. Bönnemann, H.; Brinkmann, R.; Kinge, S.; Ely, T.O.; Armand, M. Chloride free Pt- and PtRu-nanoparticles stabilised by "Armand's Ligand" as precursors for fuel cell catalysts. Fuel Cells 2004, 4, 289-296. [CrossRef]

14. Horacio, J.S.; Carlos, S.; Emilia, M. Friendly Conditions Synthesis of Platinum Nanoparticles Supported on a Conducting Polymer: Methanol Electrooxidation. J. Phys. Chem. C 2007, 111, 12454-12460. 
15. Slanac, D.A.; Li, L.; Mayoral, A.; Yacaman, M.J.; Manthiram, A.; Stevenson, K.J.; Johnston, K.P. Atomic resolution structural insights into PdPt nanoparticle-carbon interactions for the design of highly active and stable electrocatalysts. Electrochim. Acta 2012, 64, 35-45. [CrossRef]

16. Gabe, A.; García-Aguilar, J.; Berenguer-Murcia, Á.; Morallón, E.; Cazorla-Amorós, D. Key factors improving oxygen reduction reaction activity in cobalt nanoparticles modified carbon nanotubes. Appl. Catal. B Environ. 2017, 217, 303-312. [CrossRef]

17. Zhu, C.; Fu, S.; Song, J.; Shi, Q.; Su, D.; Engelhard, M.H.; Li, X.; Xiao, D.; Li, D.; Estevez, L.; et al. Self-Assembled Fe-N-Doped Carbon Nanotube Aerogels with Single-Atom Catalyst Feature as High-Efficiency Oxygen Reduction Electrocatalysts. Small 2017, 13, 1603407-1603413. [CrossRef] [PubMed]

18. Yongyong, J.; Panpan, H.; Jun, R.; Zhong, L. Single Atom Catalysis: Concept, Method and Application. Prog. Chem. 2015, 27, 1689-1704.

19. Li, W.; Liang, C.; Qiu, J.; Zhou, W.; Han, H.; Wei, Z.; Sun, G.; Xin, Q. Carbon nanotubes as support for cathode catalyst of a direct methanol fuel cell. Carbon 2002, 40, 787-803. [CrossRef]

20. Shao, Y.; Yin, G.; Gao, Y.; Shi, P. Durability Study of Pt/C and Pt/CNTs Catalysts under Simulated PEM Fuel Cell Conditions. J. Electrochem. Soc. 2006, 153, A1093-A1097. [CrossRef]

21. Rao, C.V.; Cabrera, C.R.; Ishikawa, Y. In Search of the Active Site in Nitrogen-Doped Carbon Nanotube Electrodes for the Oxygen Reduction Reaction. J. Phys. Chem. Lett. 2010, 1, 2622-2627. [CrossRef]

22. Cao, T.; Wang, D.; Zhang, J.; Cao, C.; Li, Y. Bamboo-Like Nitrogen-Doped Carbon Nanotubes with Co Nanoparticles Encapsulated at the Tips: Uniform and Large-Scale Synthesis and High-Performance Electrocatalysts for Oxygen Reduction. Chemistry 2015, 21, 14022-14029. [CrossRef] [PubMed]

23. Liu, Z.; Gan, L.M.; Hong, L.; Chen, W.; Lee, J.Y. Carbon-supported Pt nanoparticles as catalysts for proton exchange membrane fuel cells. J. Power Sources 2005, 139, 73-78. [CrossRef]

24. Kim, K.S.; Winogard, N. X-ray photoelectron spectroscopic studies of nickel-oxygen surfaces using oxygen and argon ion-bombardment. J. Am. Chem. Soc. 1974, 43, 625-643. [CrossRef]

25. Gunji, T.; Saravanan, G.; Tanabe, T.; Tsuda, T.; Miyauchi, M.; Kobayashi, G.; Abe, H.; Matsumoto, F. Long-term, stable, and improved oxygen-reduction performance of titania-supported $\mathrm{PtPb}$ nanoparticles. Catal. Sci. Technol. 2014, 4, 1436-1445. [CrossRef]

26. He, W.; Chen, M.; Zou, Z.; Li, Z.; Zhang, X.; Jin, S.-A.; You, D.J.; Pak, C.; Yang, H. Oxygen reduction on $\mathrm{Pd}_{3} \mathrm{Pt}_{1}$ bimetallic nanoparticles highly loaded on different carbon supports. Appl. Catal. B Environ. 2010, 97, 347-353. [CrossRef]

27. Xiong, Y.; Xiao, L.; Yang, Y.; DiSalvo, F.J.; Abruña, H.D. High-Loading Intermetallic $\mathrm{Pt}_{3} \mathrm{Co} / \mathrm{C}$ Core-Shell Nanoparticles as Enhanced Activity Electrocatalysts toward the Oxygen Reduction Reaction (ORR). Chem. Mater. 2018, 30, 1532-1539. [CrossRef]

28. Taylor, S.; Fabbri, E.; Levecque, P.; Schmidt, T.J.; Conrad, O. The Effect of Platinum Loading and Surface Morphology on Oxygen Reduction Activity. Electrocatalysis 2016, 7, 287-296. [CrossRef]

29. Fu, S.; Zhu, C.; Song, J.; Zhang, P.; Engelhard, M.H.; Xia, H.; Du, D.; Lin, Y. Low Pt-content ternary PdCuPt nanodendrites: An efficient electrocatalyst for oxygen reduction reaction. Nanoscale 2017, 9, 1279-1284. [CrossRef] [PubMed]

30. Liu, L.; Samjeske, G.; Nagamatsu, S.-I.; Sekizawa, O.; Nagasawa, K.; Takao, S.; Imaizumi, Y.; Yamamoto, T.; Uruga, T.; Iwasawa, Y. Enhanced Oxygen Reduction Reaction Activity and Characterization of Pt-Pd/C Bimetallic Fuel Cell Catalysts with Pt-Enriched Surfaces in Acid Media. J. Phys. Chem. C 2012, 116, 23453-23464. [CrossRef]

31. Hui, Y.; Nicolas, A.; Jean-Michel, L.; Claude, L. Tailoring, Structure, and Activity of Carbon-Supported Nanosized Pt-Cr Alloy Electrocatalysts for Oxygen Reduction in Pure and Methanol-Containing Electrolytes. J. Phys. Chem. B 2004, 108, 1938-1947.

32. Jukk, K.; Kongi, N.; Tammeveski, K.; Solla-Gullón, J.; Feliu, J.M. PdPt alloy nanocubes as electrocatalysts for oxygen reduction reaction in acid media. Electrochem. Commun. 2015, 56, 11-15. [CrossRef]

33. Gaurav, G.; Daniel, A.S.; Pavan, K.; Jaclyn, D.W.; Jeongnam, K.; Ryong, R.; Keith, J.S.; Keith, P.J. Highly Stable Pt/Ordered Graphitic Mesoporous Carbon Electrocatalysts for Oxygen Reduction. J. Phys. Chem. C 2010, 114, 10796-10805.

34. Hussain, S.; Erikson, H.; Kongi, N.; Merisalu, M.; Ritslaid, P.; Sammelselg, V.; Tammeveski, K. Heat-treatment effects on the ORR activity of Pt nanoparticles deposited on multi-walled carbon nanotubes using magnetron sputtering technique. Int. J. Hydrogen Energy 2017, 42, 5958-5970. [CrossRef] 
35. Hui, Y.; Walter, V.; Claude, L.; Nicolas, A. Structure and Electrocatalytic Activity of Carbon-Supported Pt-Ni Alloy Nanoparticles toward the Oxygen Reduction Reaction. J. Phys. Chem. B 2004, 208, 11024-11034.

36. Shao, M.; Peles, A.; Shoemaker, K. Electrocatalysis on platinum nanoparticles: Particle size effect on oxygen reduction reaction activity. Nano Lett. 2011, 11, 3714-3719. [CrossRef] [PubMed]

37. Li, L.; Liu, H.; Wang, L.; Yue, S.; Tong, X.; Zaliznyak, T.; Taylor, G.T.; Wong, S.S. Chemical Strategies for Enhancing Activity and Charge Transfer in Ultrathin Pt Nanowires Immobilized onto Nanotube Supports for the Oxygen Reduction Reaction. ACS Appl. Mater. Interfaces 2016, 8, 34280-34294. [CrossRef] [PubMed]

38. Guo, Y.; He, J.; Wang, T.; Xue, H.; Hu, Y.; Li, G.; Tang, J.; Sun, X. Enhanced electrocatalytic activity of platinum supported on nitrogen modified ordered mesoporous carbon. J. Power Sources 2011, 196, 9299-9307. [CrossRef]

39. Zhang, L.; Zheng, N.; Gao, A.; Zhu, C.; Wang, Z.; Wang, Y.; Shi, Z.; Liu, Y. A robust fuel cell cathode catalyst assembled with nitrogen-doped carbon nanohorn and platinum nanoclusters. J. Power Sources 2012, 220, 449-454. [CrossRef]

(c) 2018 by the authors. Licensee MDPI, Basel, Switzerland. This article is an open access article distributed under the terms and conditions of the Creative Commons Attribution (CC BY) license (http://creativecommons.org/licenses/by/4.0/). 